\title{
Excessive gestational calorie intake in sows regulates early postnatal adipose tissue development in the offspring
}

\author{
Kolapo M. Ajuwon ${ }^{1 *}$, Emily J. Arentson-Lantz ${ }^{2,3}$ and Shawn S. Donkin ${ }^{1}$
}

\begin{abstract}
Background: Many pregnancies in the United States are associated with maternal calorie overconsumption. Few data exist that track the impact of maternal and offspring calorie consumption on the risks for obesity development.

Methods: To determine the effects of maternal calorie intake during gestation on programming for adiposity in the offspring, pregnant gilts were fed either a normal (NE) or high (HE) energy diet to induce higher than normal (30\% increase) pregnancy weight gain and the profile of genes related to adipose tissue development was determined in the subcutaneous adipose tissue of the offspring. Gilts were fed the same lactation diet after farrowing and piglets were allowed to suckle from their mothers. Offspring were also fed either a normal energy (NE) or a high energy (HE) diet after weaning ( 3 weeks of age). Offspring were sacrificed at 48 h, 3 weeks and 3 months of age and the subcutaneous adipose tissue obtained for gene expression analysis by RT-PCR.

Results: Gilts on the HE diet had higher pregnancy weight gain and backfat thickness than those on the NE diet. Expression of adipogenic genes, such as peroxisome proliferator activated receptor (PPAR) $\gamma$ and CCAAT enhancer binding protein (CEBP) a was not different between offspring from NE and HE mothers at $48 \mathrm{~h}$ after birth, but they were higher $(P<0.05)$ at 3 weeks in the offspring from HE mothers than NE. Steroid receptor coactivator 1 (SRC1) expression was higher in HE offspring at $48 \mathrm{~h}$, but not different at weaning $(P<0.05)$. Inhibitors of wnt signaling, soluble frizzled related protein (SFRP) 4 and 5 were also higher in HE offspring at 3 weeks. The expression of PPARY corepressors, sirtuin 1 (Sirt1, NAD-dependent deacetylase sirtuin-1) and nuclear receptor co-repressor 1 (NCoR1), was higher $(P<0.05)$ in HE offspring at weaning. At 3 months, there were no effects of maternal diets on offspring adipose tissue gene expression pattern, but animals on the postweaning HE diet had a higher $(P<0.05)$ expression of SFRP5, WNT5a, lower SFRP5NNN5a and TNFa.
\end{abstract}

Conclusions: Effects of maternal calorie consumption on adipose tissue genes in the early postnatal life was transient in this study. Postweaning diet was more effective in changing offspring adipose tissue gene expression pattern and adiposity in the early postnatal period.

Keywords: Maternal nutrition, Adipose, PPARy and Wnt signaling

\section{Background}

Many pregnancies in the US are associated with maternal gestational weight gain (GWG) in excess of recommendations. This is linked with an increased risk for larger for gestational age (LGA) offspring [1-3]. The effects of maternal GWG persist into early childhood and are associated with childhood adiposity, a risk of the

\footnotetext{
* Correspondence: kajuwon@purdue.edu

'Department of Animal Sciences, Lilly Hall of Life Science, Purdue University,

915 W. State Street, West Lafayette, IN 47907-2054, USA

Full list of author information is available at the end of the article
}

offspring being overweight at multiple ages [4-7]. Greater offspring fat mass, a more direct measure of childhood adiposity, is found to be associated with excessive GWG. Excessive maternal weight gain directly affects gene expression pattern in adipose tissue, and high GWG leads to increased circulating concentrations of leptin and interleukin-6 [7], two cytokines that are highly expressed in adipose tissue, and tied to regulation of appetite and inflammation status respectively.

Currently one in five women are considered obese [8]. Pregnancy concurrent with obesity results in an altered 
intrauterine environment and poses a challenge for both the mother and fetus [9]. Maternal obesity leads to offspring with more subcutaneous fat tissue and elevated serum triglycerides, leptin and insulin despite the lack of effect maternal obesity on offspring body weight [10]. This early metabolic programming can persist to adulthood resulting in a phenotype that closely resembles the metabolic syndrome [11], manifested in abnormal glucose homeostasis [12], increased blood pressure [13], abnormal serum lipid profiles [10], increased adiposity [10], hyperphagia [12] and leptin resistance [14]. At present, the mechanism of adipose tissue programming in the offspring of obese mothers or mothers with excessive GWG is not known. This is partly because of methodological and ethical issues associated with conducting this type of research in human infants, and the lack of substantial adipose tissue in rodent pups. The pig is an excellent animal model for determining effects of maternal nutrition on adipose tissue programming because, unlike the rodent pup, the piglet has substantial adipose tissue at birth, weaning and at adulthood.

In Arentson-Lantz et al., 2014 [15] we presented liver and intestinal effects of maternal gestational calorie consumption. We hypothesized that maternal high energy intake would lead to programming of offspring for increased adiposity, which would be reflected in the gene expression pattern in adipose tissue, and that postweaning environment would temper the effect of maternal diets. Therefore, because of the potential for changes within adipose tissue of the offspring as a function of maternal diets, this work was conducted with the aim of investigating the effect maternal calorie consumption during gestation on offspring adiposity and adipose tissue programming.

\section{Methods}

\section{Animals and diets}

This study was carried out in strict accordance with the recommendations in the Guide for the Care and Use of Laboratory Animals of the National Institutes of Health. The Purdue Animal Care and Use Committee (PACUC) approved all procedures on care and use of pigs described in this study. Diets and animal care are as reported in Arentson-Lantz et al. [15]. Briefly, crossbred gilts (Landrace $\mathrm{x}$ Yorkshire terminal cross) kept at the Purdue University Animal Sciences Research and Education Center were assigned to two gestational diets; a normal energy diet (NE, $n=9)$ or a high energy diet $(\mathrm{HE}, n=5)$ diet. Diets are as presented in Tables 1 and 2 and in Arentson-Lantz et al. 2014 [15]. All diets met the National Research Council Requirements for Swine (1998). As commonly practiced in the in the industry, gilts were limit-fed such that those on the NE diet received $2.05 \mathrm{~kg}$ of feed per day, the HE animals received $3.0 \mathrm{~kg}$ but with uninterrupted access to water. The HE
Table 1 Maternal Diets

\begin{tabular}{|c|c|c|c|}
\hline Ingredients & $\mathrm{NE}^{5}$ & $\mathrm{HE}^{6}$ & Lactation \\
\hline Corn, g/kg & 52.8 & 74 & 60.9 \\
\hline Soybean meal, g/kg & 12.2 & 6.5 & 24.1 \\
\hline Dried Distillers Grains, & 30 & 15 & 7.5 \\
\hline Swine Grease, g/kg & 1 & 1.65 & 3 \\
\hline Limestone, g/kg & 1.55 & 1.06 & 1.44 \\
\hline MonoCal, g/kg & 0.75 & 0.5 & 1.42 \\
\hline Swine Vitamin Premix', & 0.25 & 0.17 & 0.25 \\
\hline Sow Vitamin Premix ${ }^{2}, \mathrm{~g} / \mathrm{kg}$ & 0.25 & 0.17 & 0.25 \\
\hline Selenium 600 Premix $^{3}$, & 0.05 & 0.035 & 0.05 \\
\hline Total Mineral Premix ${ }^{4}$, & 0.125 & 0.85 & 0.125 \\
\hline Phytase, g/kg & 0.1 & 0.1 & 0.1 \\
\hline Salt, g/kg & 0.5 & 0.35 & 0.5 \\
\hline Rabon Larvacide, g/kg & 0.13 & 0.13 & 0.13 \\
\hline Diffusion Plus, g/kg & 0.25 & 0.25 & 0.25 \\
\hline Total intake, kg/day & 2.05 & 3 & ad lib \\
\hline Total Protein, g/day & 370 & 395 & ND7 \\
\hline Total Lysine, g/day & 16.03 & 15.8 & $\mathrm{ND}^{7}$ \\
\hline Total Carbohydrate, g/day & 741 & 1457 & $\mathrm{ND}^{7}$ \\
\hline Total Fat, g/day & 119 & 178 & $\mathrm{ND}^{7}$ \\
\hline Metabolizable Energy, & 6761 & 10144 & $\mathrm{ND}^{7}$ \\
\hline
\end{tabular}

${ }^{1}$ Purdue Swine Vitamin Premix: Vitamin A, 544,680 IU/kg; Vitamin D3, 54,448 IU/kg; Vitamin E, 3631 IU/kg; Mendione (Vitamin K), $182 \mathrm{mg} / \mathrm{kg}$; Vitamin B12, $3.2 \mathrm{mg} / \mathrm{kg}$; Riboflavin, $726 \mathrm{mg} / \mathrm{kg}$; d-Pantothenic Acid, 1,816 mg/kg; Niacin, $2,723 \mathrm{mg} / \mathrm{kg}$

${ }^{2}$ Sow Vitamin Premix: KSU Sow Vitamin Add Pack with CarniChrome from ADM ${ }^{\otimes}$ (Biotin, $18.1 \mathrm{mg} / \mathrm{kg}$; Folic Acid, $136 \mathrm{mg} / \mathrm{kg}$; Choline, 45,390 mg/kg; Pyridoxine, 409 mg/kg; Vitamin E, 1,816 IU/kg; Chromium, $16.3 \mathrm{mg} / \mathrm{kg}$; Carnitine, 4,805 mg/kg)

${ }^{3}$ Selenium-600 premix: Calcium, 28-31 \%; Selenium, $0.06 \%$ equivalent to $123.6 \mathrm{mg} / \mathrm{kg}$

${ }^{4}$ Purdue Non-Sulfur Trace Mineral Premix: Iron, $51.05 \%$; Zinc, $20.73 \%$; Manganese, $2.86 \%$; Copper, $1.56 \%$; lodine, $0.046 \%$

${ }^{5}$ Diet used for NE treatment during gestation

${ }^{6}$ Diet used for HE treatment during gestation

${ }^{7}$ Not determined, lactation diet was fed for ad libitum intake

diet supplied $50 \%$ more metabolizable energy than the NE diet. Backfat at the 12th rib was measured at the end of gestation using ultra sound technique (Aloka American Ltd, Wallington, CT). Serum samples were collected from the gilts on days 21 (baseline), 44 and 77 of gestation. Whole blood was centrifuged at $4{ }^{\circ} \mathrm{C}$ at $3000 \mathrm{rpm}$ for $15 \mathrm{~min}$ for collection of serum. Serum blood glucose concentration was determined with an automatic glucometer (Freestyle, Alameda, CA). Serum free fatty acid was determined using the free fatty acids, half micro test kit (Roche Diagnostics, Indianapolis, IN). Serum insulin was determined using the Mercodia porcine insulin ELISA kit (Mercodia, Uppsala, Sweden) according to the manufacturer's instructions.

\section{Post-farrowing treatments}

At farrowing, all gilts were fed the same lactation diet (Table 2). Piglet offspring were weaned on day 21 . 
Table 2 Nutrient composition of piglet diets

\begin{tabular}{|c|c|c|c|c|c|}
\hline \multirow[t]{2}{*}{ Ingredient } & \multirow[t]{2}{*}{ Phase 1 (All pigs) } & \multicolumn{2}{|c|}{ Phase 2 (4-6weeks) } & \multicolumn{2}{|c|}{ Phase 4 (6-12 weeks) } \\
\hline & & $\overline{\mathrm{NE}}$ & $\mathrm{HE}^{4}$ & $\overline{\mathrm{NE}}$ & $\mathrm{HE}$ \\
\hline Corn, g/kg & 32.26 & 32.26 & 37.355 & 60.985 & 52.985 \\
\hline Soybean Meal, g/kg & 13.72 & 13.72 & 19 & 24.64 & 24.64 \\
\hline Dried distillers grains, $\mathrm{g} / \mathrm{kg}$ & - & - & - & 7.5 & 7.5 \\
\hline Soybean Oil, g/kg & 5 & 5 & 5 & - & 5 \\
\hline Limestone, g/kg & 0.72 & 0.72 & 0.61 & 1.35 & 1.35 \\
\hline MonoCal Phosphate, g/kg & 0.53 & 0.53 & 0.75 & 0.74 & 0.74 \\
\hline Swine Vitamin Premix', g/kg & 0.25 & 0.25 & 0.25 & 0.25 & 0.25 \\
\hline Swine Total Mineral Premix 2 g/kg & 0.125 & .0125 & 0.125 & 0.125 & 0.125 \\
\hline Selenium 600 Premix $^{3}, \mathrm{~g} / \mathrm{kg}$ & 0.05 & 0.05 & 0.05 & 0.05 & 0.05 \\
\hline Dried Whey, g/kg & 25 & 25 & 25 & - & - \\
\hline Lactose, $\mathrm{g} / \mathrm{kg}$ & 5 & 5 & - & - & - \\
\hline Fish Meal, g/kg & 4 & 4 & 4 & - & - \\
\hline Phytase (600 PU/g), g/kg, & 0.1 & 0.1 & 0.1 & 0.1 & 0.1 \\
\hline Salt, g/kg & 0.25 & 0.25 & 0.25 & 0.35 & 0.35 \\
\hline Blood meal, g/kg & 6.5 & 6.5 & 3.75 & - & - \\
\hline Zinc Oxide, g/kg & 0.375 & 0.375 & 0.375 & - & - \\
\hline Soy Concentrate, g/kg & 4 & 4 & 2.5 & - & - \\
\hline Carbadox (10 g/lb), g/kg, g/kg & 0.25 & 0.25 & 0.25 & 1 & 1 \\
\hline Lysine-HCL, g/kg & 0.11 & 0.11 & 0.25 & 0.4 & 0.4 \\
\hline DL-Methionine, $\mathrm{g} / \mathrm{kg}$ & 0.2 & 0.2 & 0.22 & 0.12 & 0.12 \\
\hline L-Threonine, g/kg & 0.04 & 0.04 & 0.12 & 0.16 & 0.16 \\
\hline L-Tryptophan, g/kg & - & - & 0.02 & 0.3 & 0.3 \\
\hline Rabon Larvacide, g/kg & 0.025 & 0.025 & 0.25 & 0.25 & 0.25 \\
\hline Banmith dewormer, g/kg & - & - & - & 0.1 & 0.1 \\
\hline Copper Sulfate, g/kg & - & - & - & 0.075 & 0.075 \\
\hline Crude Protein, kcal/kg & 23.96 & 23.96 & 22.8 & 19.4 & 17.9 \\
\hline Total Lysine, \% & 1.73 & 1.73 & 1.65 & 1.29 & 1.21 \\
\hline Metabolizable Energy, kcal/kg & 3545 & 3545 & 3522 & 3395 & 3771 \\
\hline
\end{tabular}

${ }^{1}$ Purdue Swine Vitamin Premix: Vitamin A, 544,680 IU/kg; Vitamin D3, 54,448 IU/kg; Vitamin E, 3631 IU/kg; Mendione (Vitamin K), 182 mg/kg; Vitamin B12, 3.2 mg/kg; Riboflavin, $726 \mathrm{mg} / \mathrm{kg}$; d-Pantothenic Acid, 1,816 mg/kg; Niacin, 2,723 mg/kg

${ }^{2}$ Purdue Non-Sulfur Trace Mineral Premix: Iron, $51.05 \%$; Zinc, 20.73 \%; Manganese, 2.86 \%; Copper, $1.56 \%$; lodine, $0.046 \%$

${ }^{3}$ Selenium 600-Premix: Calcium, 28-31\%; Selenium, $0.06 \%$ equivalent to $123.6 \mathrm{mg} / \mathrm{kg}$

${ }^{4} \mathrm{HE}$ Phase 2 diet was made by mixing $909 \mathrm{~kg}$ of the control Phase 2 diet base with $68 \mathrm{~kg}$ of $7 \%$ protein, $60 \%$ fat milk replacer add-in

Immediately after weaning, piglets were kept on a common diet for 7 days after which they were assigned either to a post-weaning normal energy diet (NE) or high energy diet (HE) (Table 2). All piglets were kept in pens within an environmentally controlled house. A total of eighteen piglets from NE gilts were assigned to postweaning diets (10 to NE and 8 to HE). Twelve piglets from the HE gilts were assigned (6 each NE and HE) to post-weaning diets (Fig. 1). Body weights of piglets was taken weekly during the grower phase and biweekly during the finisher phase. Equal number of males and female piglets were assigned to each treatment.

\section{Sample collection}

Milk was collected from sows at day 14 of lactation. Sows were given $10 \mathrm{IU}$ of oxytocin via intramuscular route to stimulate milk let-down. Milk was manually expressed by a trained operator. Samples were sent to a commercial laboratory (Dairy One, Ithaca, NY) and analyzed for fats, solids and energy. To conduct gene expression analysis of piglet tissues, piglets were killed at each collection period ( $48 \mathrm{~h}, 3$ weeks and 12 weeks) either with intramuscular injection of atropine, tiletaminezolazepam, and xylazine followed by pneumothorax and cardiectomy or by $\mathrm{CO}_{2}$ exposure followed by severance 


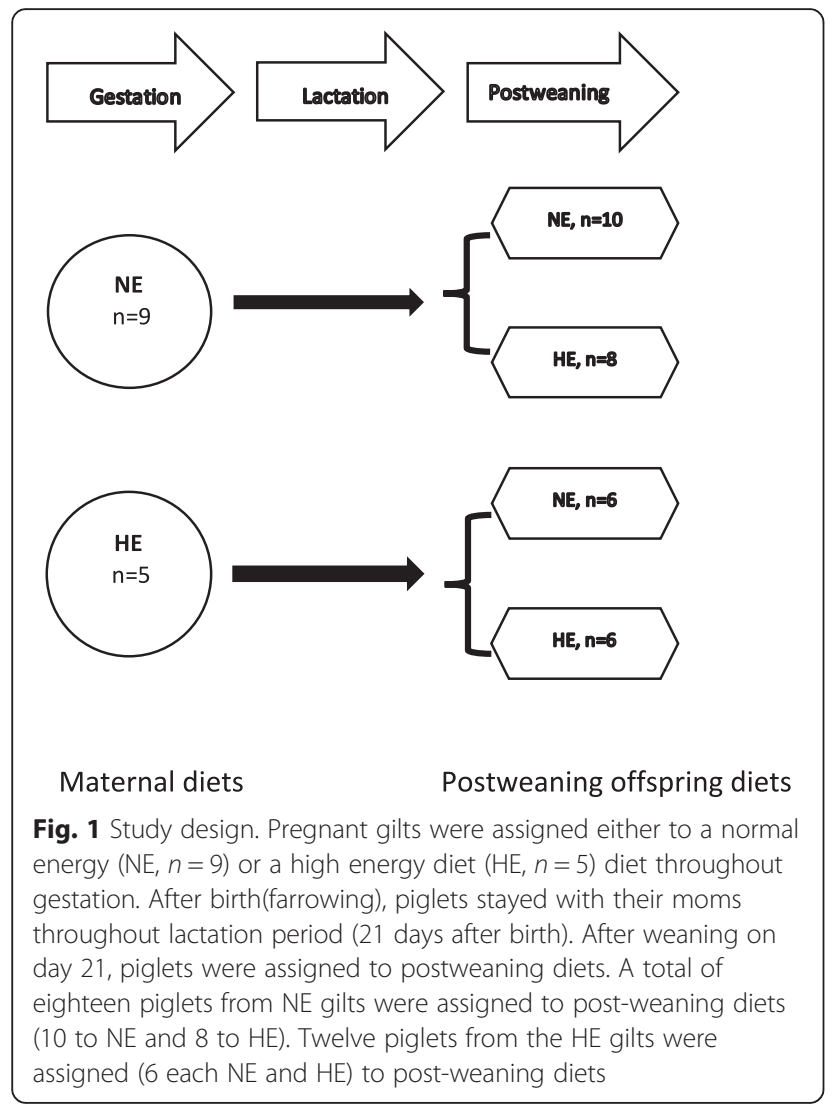

of the jugular vein and exsanguination. This ensured pain to animals was minimized before death. Subcutaneous adipose tissue samples were collected from above the shoulders. Serum samples were collected at each of these time points. Samples were snap-frozen in liquid nitrogen and in $-80{ }^{\circ} \mathrm{C}$ freezer for long-term storage for RNA extraction and RT-PCR. Piglet backfat thickness was manually measured immediately after euthanasia at 12 weeks above the shoulder (interscapular region) along the midline of the split carcass [16]. To allow consistency, this was done by a single operator.

\section{RNA isolation and CDNA synthesis}

After the isolation of RNA with the QIAzol reagent, it was dissolved in nuclease free water (Ambion, Austin, TX) and concentrations were determined using a Nanodrop reader (Thermo Scientific, Waltham, MA). RNA samples were subjected to electrophoresis on a $1 \%$ agarose gel as a check of RNA integrity. One microgram of total RNA was reverse transcribed with MMLV reverse transcriptase (Promega, Madison, WI).

\section{Real-time PCR analysis}

Real-time quantitative PCR was performed using the MyiQ real-time PCR detection system (Bio-Rad, Hercules, CA) using the SYBR mix RT-PCR mix (SABiosciences,
Frederic, MD). The mRNA abundance of different genes was determined from the threshold cycle $(\mathrm{Ct})$ for the respective genes and normalized against the $\mathrm{Ct}$ for $18 \mathrm{~S}$ using the $\Delta \Delta \mathrm{Ct}$ method. Primers used for RT-PCR are listed in Table 5.

\section{Data analysis}

Data were examined for normality and analyzed using the GLM procedure (SAS Inst. Inc., Cary, NC). When there was significant main effect, separation of means was accomplished with the Tukey mean separation procedure. Differences were considered significant at $P<$ 0.05 and at $P<0.10$ for tendency towards significance. Values in texts are means \pm SEM.

\section{Results}

\section{Maternal responses}

The maternal growth responses show that gilts on the HE diet gained significantly more (37\%) weight than those on the NE diet ( 41.9 vs. $29.6 \mathrm{~kg}$ ). This was well within our expected $30 \%$ more weight gain in gilts on the HE diet. Backfat accumulation was also higher in gilts on the HE diet than NE (7.6 vs. $4.30 \mathrm{~mm}$ ) [15]. Thus the increased weight gain in gilts on the HE diet was associated with increased adiposity. Thus this model recapitulates the excessive gestational weight gain and adiposity in some pregnant women in the US. Serum glucose was also significantly higher in HE gilts (88.8 vs.

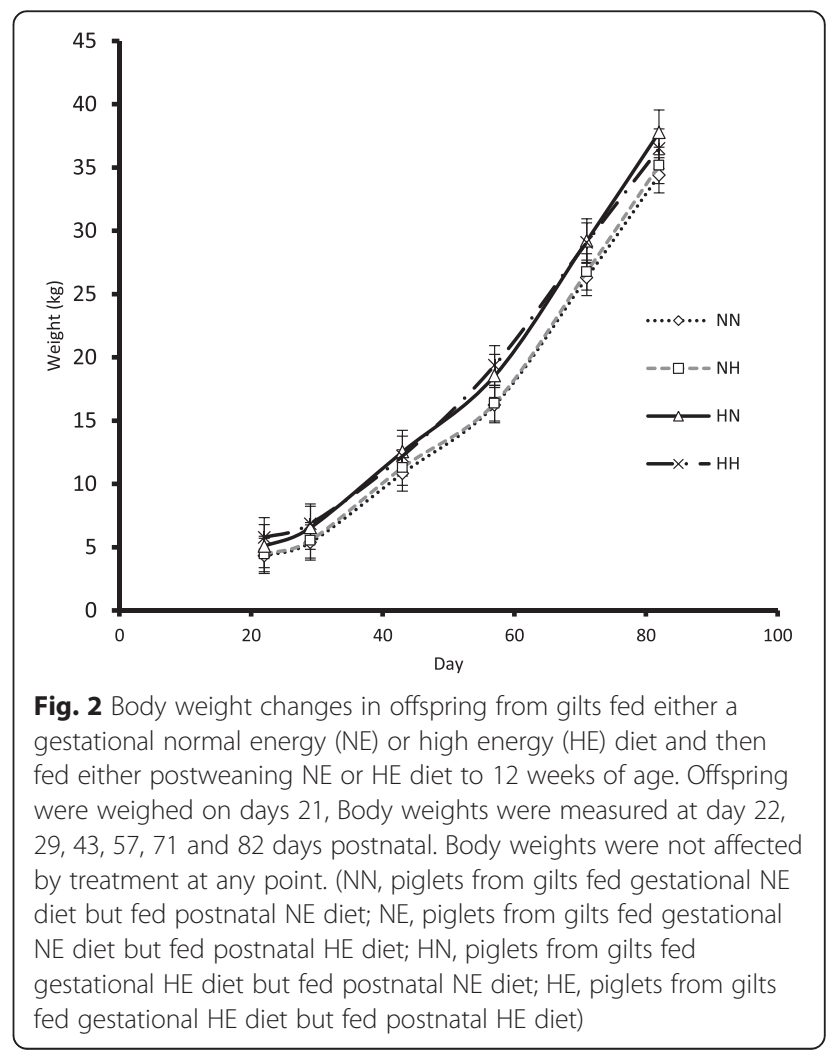


$78.6 \mathrm{mg} / \mathrm{dl})(P<0.05)$, but the concentrations of insulin and NEFA were not affected by diet. In addition, milk from the HE gilts had a higher concentration of fat $(8.79$ vs. $7.2 \%$ ), solids (19.9 vs. $18.2 \%$ ) and energy (502 vs. $443 \mathrm{KJ} / \mathrm{g}$ ) than from NE gilts [15]. Thus gestational HE intake resulted in milk with higher nutrient content than consumption of the NE diet.

\section{Offspring responses}

Weight gain in offspring was not different (Fig. 2) from birth to 12 weeks. However, offspring on the postnatal HE diet had more backfat, irrespective of their maternal dietary group (Fig. 3). Serum glucose was not affected by maternal treatment, but was higher ( $91 \mathrm{vs.} 67 \mathrm{mg} / \mathrm{dL}$ ) in offspring on the postweaning HE diet than those on the NE diet. Thus serum metabolite parameters may not be good predictors of long-term effects of maternal and postweaning diets at 12 weeks of age in pigs.

\section{Adipose tissue gene expression}

At $48 \mathrm{~h}$ after birth, genes such as SRC1 (steroid receptor coactivator 1), SFRP2 (secreted frizzled-related

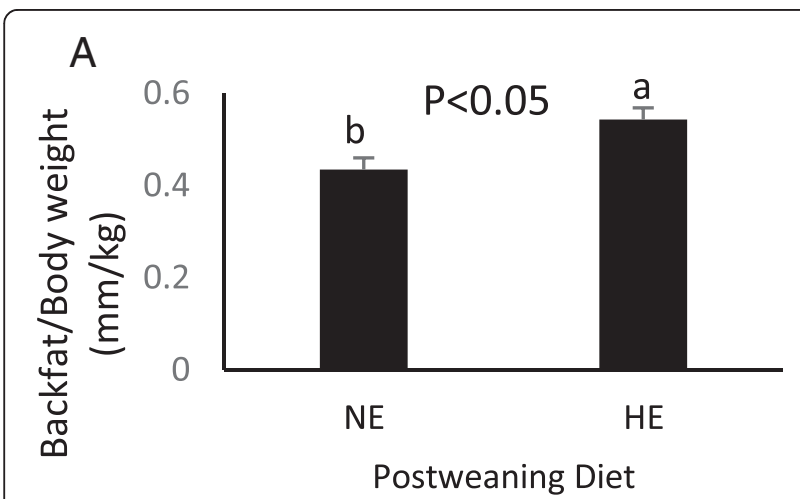

B

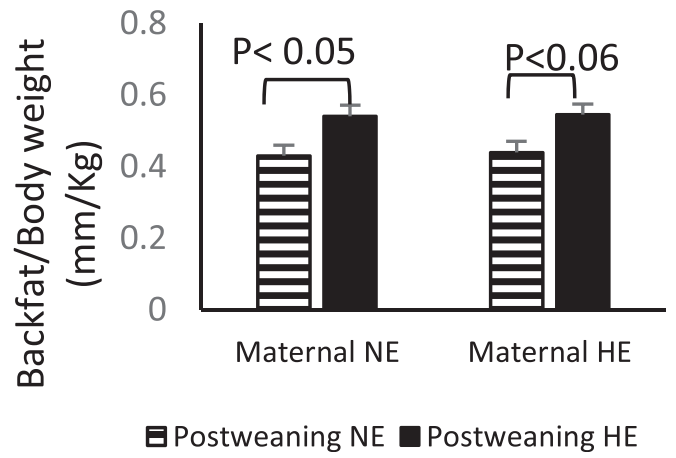

Fig. 3 Backfat depth of offspring measured at day 84 (12 weeks postnatal). Backfat was measured at the 12th rib. a Postweaning diet effect. b separated treatment groups. Bars represent mean \pm SEM. Superscript letters represent significant mean differences $(P<0.05)$. Offspring weaned to HE had higher backfat thickness $(P<0.05)$ protein 2) and SET domain containing (lysine methyltransferase 8 (SETD8) were significantly higher $(P<$ $0.05)$ in the adipose tissue of piglets from $\mathrm{HE}$ gilts, whereas there was a tendency $(P<0.06)$ for a higher HSD1 in the piglets from HE gilts as well (Table 3).

Table 3 Subcutaneous adipose tissue gene expression $48 \mathrm{~h}$ post birth

\begin{tabular}{cccc}
\hline Gene & $\mathrm{NE} \pm \mathrm{SE}$ & $\mathrm{HE} \pm \mathrm{SE}$ & $P$-value \\
\hline Differentiation related genes & & \\
PREF1 & $1.18 \pm 0.14$ & $1.06 \pm 0.18$ & 0.59 \\
CEBPa & $1.06 \pm 0.12$ & $1.21 \pm 0.16$ & 0.45 \\
PPARY & $1.27 \pm 0.18$ & $1.16 \pm 0.24$ & 0.71
\end{tabular}

Proliferation related gene

$\begin{array}{llll}\text { CCDN1 } & 1.32 \pm 0.18 & 1.09 \pm 0.24 & 0.45\end{array}$

Inflammatory genes

$\begin{array}{llll}\text { IL6 } & 1.04 \pm 0.08 & 0.99 \pm 0.12 & 0.30 \\ \text { TNFa } & 2.82 \pm 0.77 & 4.02 \pm 1.18 & 0.31 \\ \text { IL1 } \beta & 6.97 \pm 2.35 & 11.10 \pm 3.32 & 0.28\end{array}$

Genes involved in fatty acid and gene regulation

$\begin{array}{llll}\text { FABP4 } & 1.23 \pm 0.22 & 1.31 \pm 0.29 & 0.61 \\ \text { IGF1 } & 2.50 \pm 0.66 & 1.25 \pm 0.49 & 0.36 \\ \text { IGFR1 } & 0.80 \pm 0.22 & 1.22 \pm 0.17 & 0.10 \\ \text { GHR } & 0.90 \pm 0.38 & 1.56 \pm 0.28 & 0.12 \\ \text { GCCR } & 1.99 \pm 0.48 & 1.14 \pm 0.36 & 0.35 \\ \text { HSD1 } & 0.87 \pm 0.16 & 1.20 \pm 0.12 & 0.06 \\ \text { SRC1 } & 0.80 \pm 0.19 & 1.33 \pm 0.14 & 0.03^{*} \\ \text { NCOR1 } & 1.01 \pm 0.17 & 1.50 \pm 0.23 & 0.18 \\ \text { PGC1a } & 1.62 \pm 0.49 & 2.72 \pm 0.69 & 0.11 \\ \text { SIRT1 } & 1.51 \pm 0.49 & 2.77 \pm 0.70 & 0.11 \\ \text { SERPINE1 } & 1.46 \pm 0.44 & 1.67 \pm 0.32 & 0.38\end{array}$

Wnt signaling related

$\begin{array}{llll}\text { Wnt5a } & 2.35 \pm 0.72 & 3.66 \pm 1.02 & 0.31 \\ \text { Wnt3a } & 14.14 \pm 3.97 & 5.79 \pm 2.96 & 0.11 \\ \text { Wnt10b } & 2.3 \pm 0.52 & 1.13 \pm 0.39 & 0.12 \\ \text { FZD1 } & 3.13 \pm 0.82 & 1.44 \pm 0.61 & 0.15 \\ \text { FZD2 } & 1.89 \pm 0.42 & 1.04 \pm 0.31 & 0.26 \\ \text { FZD7 } & 1.45 \pm 0.37 & 1.92 \pm 0.49 & 0.43 \\ \text { SFRP2 } & 1.05 \pm 0.30 & 2.06 \pm 0.40 & 0.05^{*} \\ \text { SFRP4 } & 1.27 \pm 0.25 & 1.29 \pm 0.33 & 0.99 \\ \text { SFRP5 } & 2.85 \pm 0.89 & 0.96 \pm 1.16 & 0.18 \\ \text { Wnt5a/SFRP5 } & 7.87 \pm 3.23 & 10.09 \pm 4.42 & 0.31\end{array}$

Histone methylases related genes

$\begin{array}{llll}\text { SETDB1 } & 1.28 \pm 0.25 & 1.04 \pm 0.32 & 0.36 \\ \text { SETD8 } & 1.01 \pm 0.25 & 1.91 \pm 0.34 & 0.05^{*}\end{array}$

$\mathrm{NE}$, gestational normal energy diet. $\mathrm{HE}$, gestational High energy diet. Data are presented as least-square means \pm SE. Asterisk (*) within rows indicate significant differences $(P<0.05)$ 
At weaning (Table 4), genes involved in differentiation, PPARY (peroxisome proliferator activated receptor) and CEBP $\alpha$ (CCAAT Enhancer binding protein $\alpha)$, were higher in piglets $(P<0.05)$ from $\mathrm{HE}$ dams. In addition, FABP4 (fatty acid binding protein 4), involved in fatty acid transport, was induced under HE diet. Genes such as NCOR1 (nuclear receptor corepressor 1), SIRT1, GCCR (glucocorticoid receptor), FZD2 (frizzled class receptor 2), Wnt inhibitors secreted frizzled-related protein 4 and 5 (SFRP4 and SFRP5) and histone methyltransferases (SETDB1 and SETD8) were higher in HE piglets than NE. However, IL1 $\beta$ (interleukin $1 \beta$ ) expression was lower
$(P<0.05)$ in $\mathrm{HE}$ piglets and there was a tendency $(P<$ 0.06) for a lower expression of Wnt3a (Table 5).

At 12 weeks, there was no longer a maternal diet effect on most genes that were affected by maternal diet at weaning. Unlike at weaning, there was no effect of maternal diet or postweaning diet effect on PPAR $\gamma$ and CEBP $\alpha$ (Fig. 4). Expression of NCOR1 was lower $(P<$ 0.05 ) in pigs on post weaning $\mathrm{HE}$ diet, but maternal diet effect was not significant. Expression of both SFRP5 and Wnt5a was higher $(P<0.05)$ in pigs on the postnatal HE diet than those on the NE diet (Fig. 5). In addition, there was a tendency $(P<0.09)$ for a lower ratio of $\mathrm{Wnt} 5 \mathrm{a} /$

Table 4 Subcutaneous adipose tissue gene expression 21 days post birth

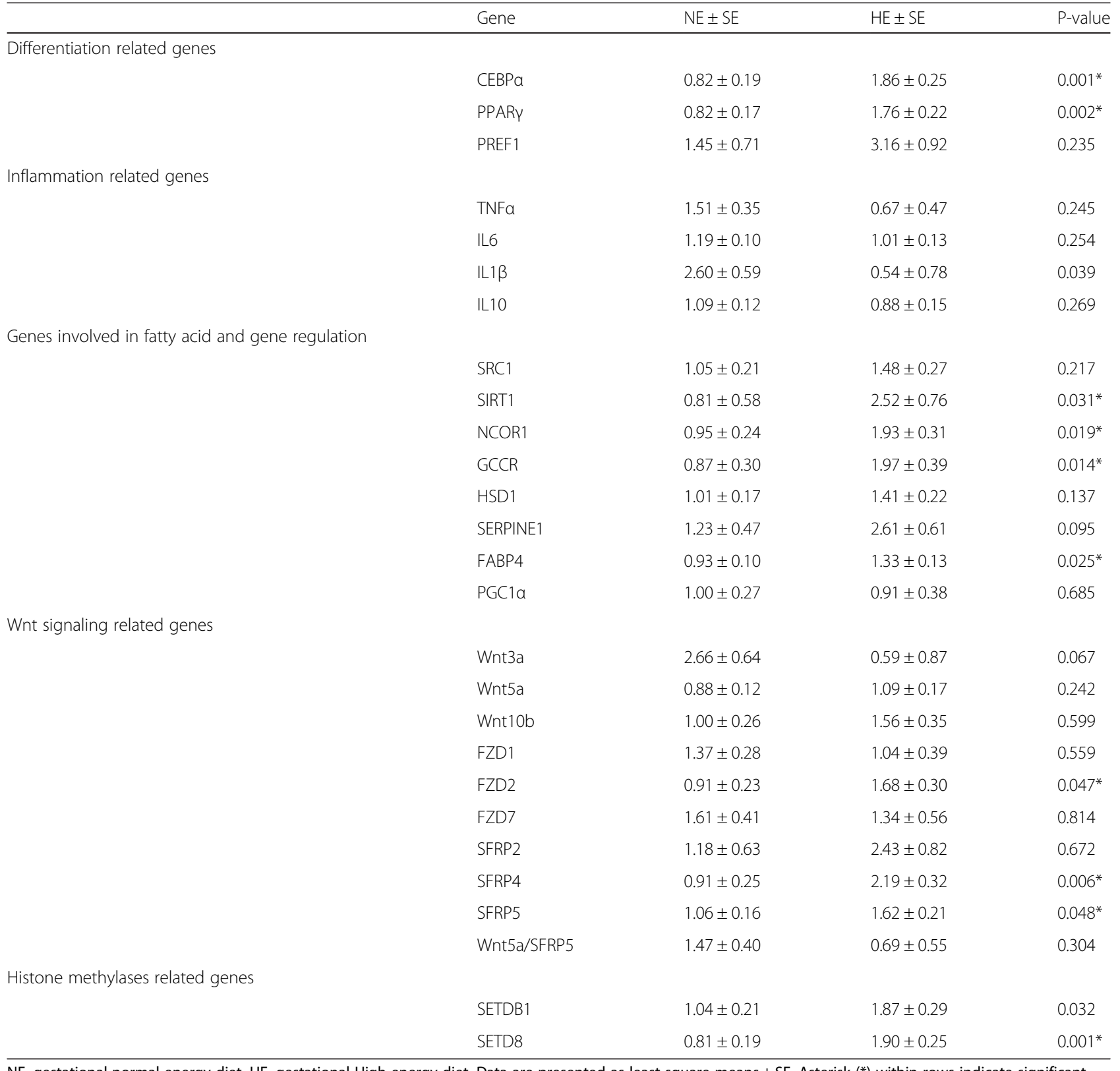

$\mathrm{NE}$, gestational normal energy diet. $\mathrm{HE}$, gestational High energy diet. Data are presented as least-square means $\pm \mathrm{SE}$. Asterisk $\left({ }^{*}\right)$ within rows indicate significant differences $(P<0.05)$ 
Table 5 List of primers used for RT-PCR

\begin{tabular}{|c|c|c|}
\hline Gene & Forward & Reverse \\
\hline 185 & 5'-ATC CCT GAG AAG TTC CAG CA-3' & 5'-CCT CCT GGT GAG GTC GAT GT-3' \\
\hline$T N F a$ & 5'-CCA CCA ACG TाT TCC TCA CT-3' & 5'-CCC AGG TAG ATG GGT TCG TA-3' \\
\hline $\operatorname{IL1B}$ & 5'-CCA AAG AGG GAC ATG GAG AA-3' & 5'-GGG CTT TTG TTC TGC TTG AG-3' \\
\hline$R O R 2$ & 5'-CTG GTG CTT CAC GCA GAA TA-3' & 5'-GCA CAT GCA GAC CAA GAA GA-3' \\
\hline IGF1 & 5'-GCA GAT AGA GCC TGC GCA ATG GA-3' & 5'-GGG AGA TGG GAG ATG TTG AGA GCA-3' \\
\hline Adiponectin & 5'-TGG AGA AAG CGC CTA TGT CT-3' & 5'-TTा GCC AGT GGT GAC ATC AT-3' \\
\hline Wnt5a & 5'-GGA CCA CAT GCA GTC CAT CG-3' & 5'-GAG GTG TTA TCC ACC GTG CT-3' \\
\hline SFRP5 & 5'-TCT TCC TCT GCT CGC TCT TC-3' & 5'-TTT GAC CAC GAA GTC ACT GG-3' \\
\hline NCOR1 & 5'-CTG ATC AGC AAG TCC AGC AG-3' & 5'-CTG TGG TAG TCC CCC TCT GA-3' \\
\hline PPARY & 5'-GCC CTT CAC CAC TGT TGA TT-3' & 5'-GTT GGA AGG CTC TTC GTG AG-3' \\
\hline CEBPa & 5'-TGG ACA AGA ACA GCA ACG AG-3' & 5'-TTG TCA CTG GTC AGC TCC AG-3' \\
\hline SETDB1 & 5'-AGG ACA CGT CCA AAT ATG GGT GCT-3' & 5'-AGA GGT GGA CCT GGT GGG GC-3' \\
\hline SETD8 & 5'-CGT GAC GAG AAA AGA AAC TCT GGG A-3' & 5'-TGG AAA AGG TGC CAG GGG GC-3' \\
\hline WNT3a & 5'-TCT GGT GGT CCC TGG CTG TGG G-3' & 5'-GCC ACG CTG GGC ATG ATC TCC-3' \\
\hline FZD1 & 5'-GAG CCA GCT AGC CGA GGG CCA-3' & 5'-GGC AGT GGG GAG AGC CCT GGT-3' \\
\hline FZD2 & 5'-GTG CCC GGC GCA CTA CAC TC-3' & 5'-CCA CGA GTG CAG CGT CTT GC-3' \\
\hline FZD7 & 5'-CCA ACG GCC TCA TGT ACT Tा-3' & 5'-ATG AAG TAG CAG CCC GAC AG-3' \\
\hline SFRP2 & 5'-ACG AGA CCA TGA AGG AGG TG-3' & 5'-ATG GTT TCG TCC AGG TCA TC-3' \\
\hline SFRP4 & 5'-GTC CAG GAC AAG AAG CAA GC-3' & 5'-ACG CTC GTT TGG AGT TTG TT-3' \\
\hline $1 L 6$ & 5'-TCT GGG TTC AAT CAG ACC TGC-3' & $5^{\prime}$-TGC ACG GCC TCG ACA TTा CCC-3' \\
\hline GCCR & 5'-GCG TCT TCA CCC TCC CTG GC-3' & 5'-TGG AAA GTC CAC CGC AAG CCT-3' \\
\hline HSD1 & 5'-CCA CCT CGT GCG CAG AAG CA-3' & 5'-TCG CCA TTT TCC CCG CCT GC-3' \\
\hline$S R C 1$ & 5'-CCT GCT TCT GGC TAC CAG TC-3' & 5'-TAT CTG CTC AGG GCA CAC AG-3' \\
\hline GHR & 5'-CCA CTG GAC AGA TGG GGT CCG T-3' & 5'-TGA GTC CAC TCT TGA GTG ACA AA-3' \\
\hline FABP4 & 5'-TGG TAC AGG TGC AGA AGT GG-3' & 5'-ATT CTG GTA GCC GTG ACA CC-3' \\
\hline SIRT1 & 5'-CCA TGG CGC TGA GGT ATA TT-3' & 5'-CTC CAA ATC CAG TTC CTC CA-3' \\
\hline WNT1OB & 5'-TTC GGG CCC GGG ATT CGA CA-3' & 5'-GCT TAG GGC CCG ACT GCA CA-3' \\
\hline SERPINE & 5'-ATT CTG GAC GCT CAG CTC AT-3' & 5'-TCC GTC ATT CCC AAG TTC TC-3' \\
\hline
\end{tabular}

SFRP5. This ratio determines the amount of available Wnt5a and the ability of Wnt to regulate adipocyte differentiation. We also observed a tendency $(P<0.08)$ for a higher IGF-1 (insulin-like growth factor 1) expression in pigs on the post weaning HE diet than those on the NE diet. Expression of neurotrophic tyrosine kinase, receptor-related 2 (ROR2), another Wnt receptor, was higher in pigs on the post weaning HE diet. In addition, the expression of TNF $\alpha$ was lower $(P<0.05)$ in pigs on postnatal HE diet than those on the NE diet (Fig. 6) Other genes such as PREF1 (preadipocyte factor 1), CCDN1(cyclin D), FABP4 (fatty acid binding protein 4), IGFR1 (insulin-like growth factor receptor 1), GHR (growth hormone receptor), GCCR, HSD1 (hydroxysteroid dehydrogenase 1), SRC1, PGC1 $\alpha$ (PPAR gamma coactivator 1), SIRT1, SERPINE (serpin peptidase inhibitor, clade E, nexin, plasminogen activator type 1), Wnt5a (wingless-type MMTV integration site family, member 5a), Wnt10b, FZD1, FZD2, FZD7, SFRP2, SFRP4, SETDB1 and SETD8 were neither affected by maternal nor post weaning diet (data not shown). Thus, compared to week 3, maternal diet had limited effect on offspring adipose tissue gene expression pattern.

\section{Discussion}

Excessive weight gain during gestation remains a major problem in many women of child-bearing age in the US and across the globe [17]. In this study we have evaluated the effect of maternal weight gain during gestation on adipose tissue programming in the offspring. Because predisposition to obesity development is affected by both maternal diet during gestation and offspring postnatal diet, we also determined the effects of postweaning nutrition on adipose tissue gene expression pattern at 12 weeks of age as a way of determining programming for future adipose tissue expansion. 


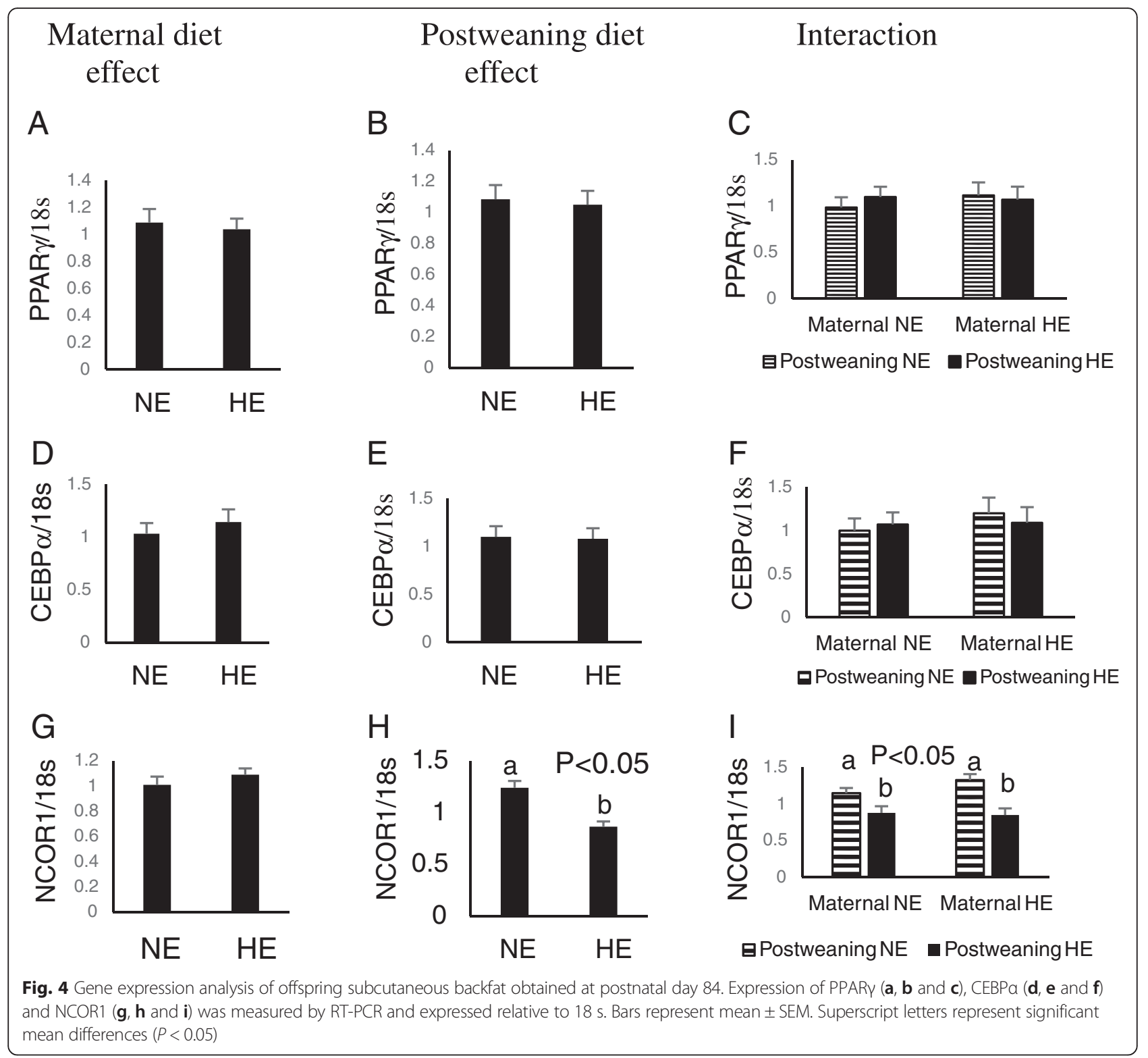

Recent estimates of pregnancy weight gain in the US project that less than half of pregnancies in the U.S. meet the IOM guidelines with a clear majority of the pregnancies gaining more than the recommended amount of weight based on pre-pregnancy BMI [18]. Recent evidence also suggests GWG is associated with increased offspring birth weight independent of genetics [19]. Fat deposition is a major component of maternal weight gain [20]. During gestation there is accumulation of protein, fat, water and minerals into the products of conception (fetus, placenta and amniotic fluid) as well as the maternal uterus, mammary gland, blood and adipose tissue [21]. Fat accretion is targeted primarily to the subcutaneous adipose tissue depots in the hips, back and upper thighs $[22,23]$ in a pattern unique to pregnancy. Therefore, results of the higher backfat accumulation in the gilts on the gestational HE diet indicate that the increased calorie consumption resulted in higher maternal adiposity. However, there was no effect of maternal diet on offspring birth weight, weaning weight or weight at 12 weeks. This is in contrast to studies where maternal calorie consumption and obesity have been shown to lead to increased offspring weight $[1,3,4]$. However, this may indicate the limitation of the experimental diets used in this study to affect offspring weights in the immediate postnatal period. The increased expression of genes such as SRC1, SFRP2, SETD8 and the trend for a higher HSD1 at $48 \mathrm{~h}$ after birth in piglets from mothers on the HE diet 


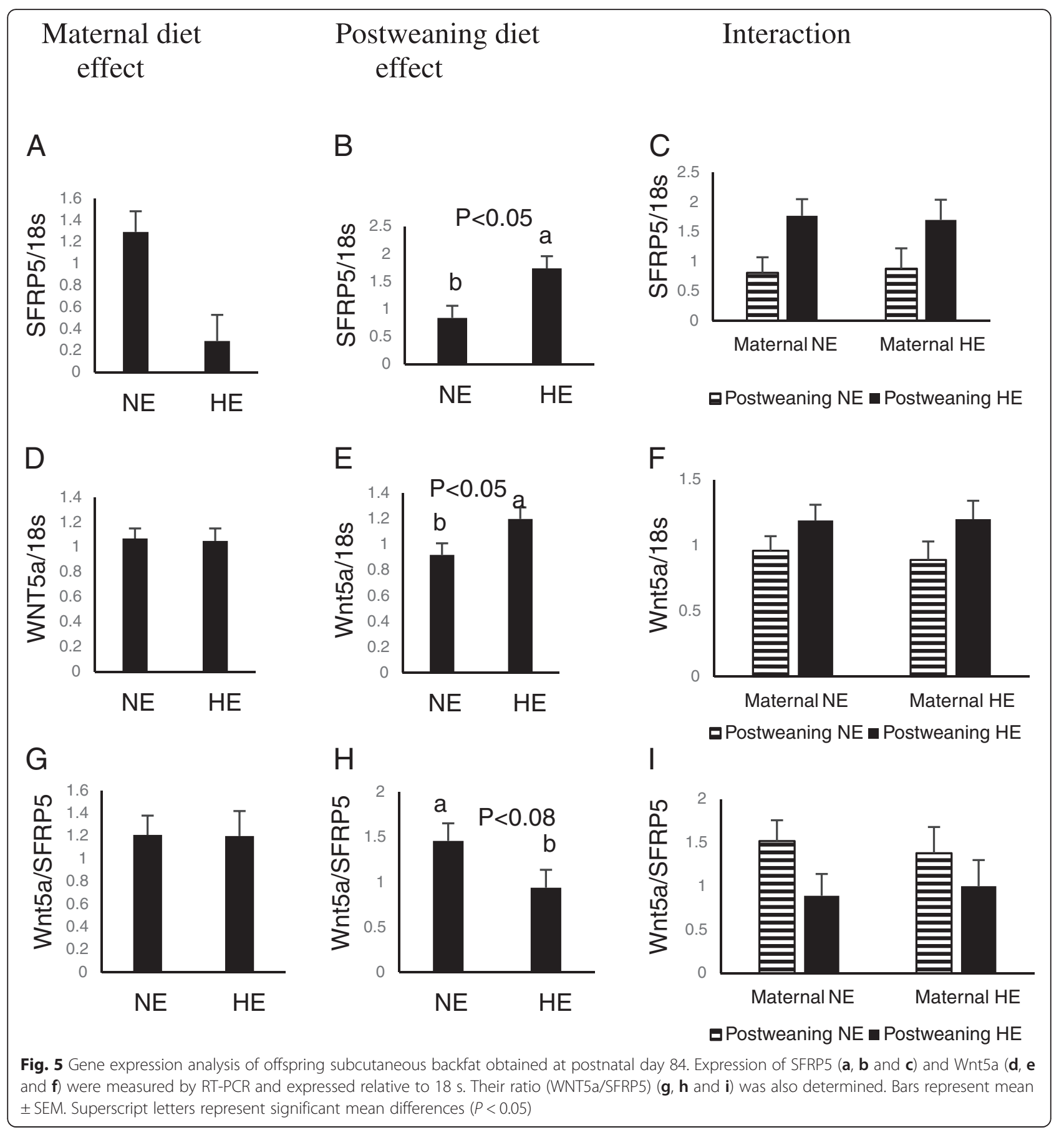

indicates unique adipose tissue effects of maternal diet. The induction of SETD8 is consistent with maternal diet causing epigenetic changes in the offspring in a way that can affect offspring adiposity. Both SETD8 and PPAR $\gamma$ co-regulate each other in a positive feedback loop during adipogenesis, and the suppression of SETD8 suppresses adipogenesis [23]. Thus, as established through surgically-induced placental insufficiency [23, 24] and diet-induced maternal obesity [25], consumption of excess energy during gestation in pigs can also result in the modification of the histone code. Additionally, SRC1 increases the transcriptional activity of PPARy [26]. Soluble frizzle related receptors (SFRP) are negative regulators of wnt signaling [27]. Their binding to wnt prevents the inhibitory effects of wnt on adipogenesis [28] and SFRP 1-4 are adipokines that are upregulated in human models of obesity [29]. Thus upregulation of SFRP2 in the adipose tissue of piglets from mothers on the HE diet is consistent programming for increased adipogenic potential in those offspring through the inhibition of wnt signaling. 


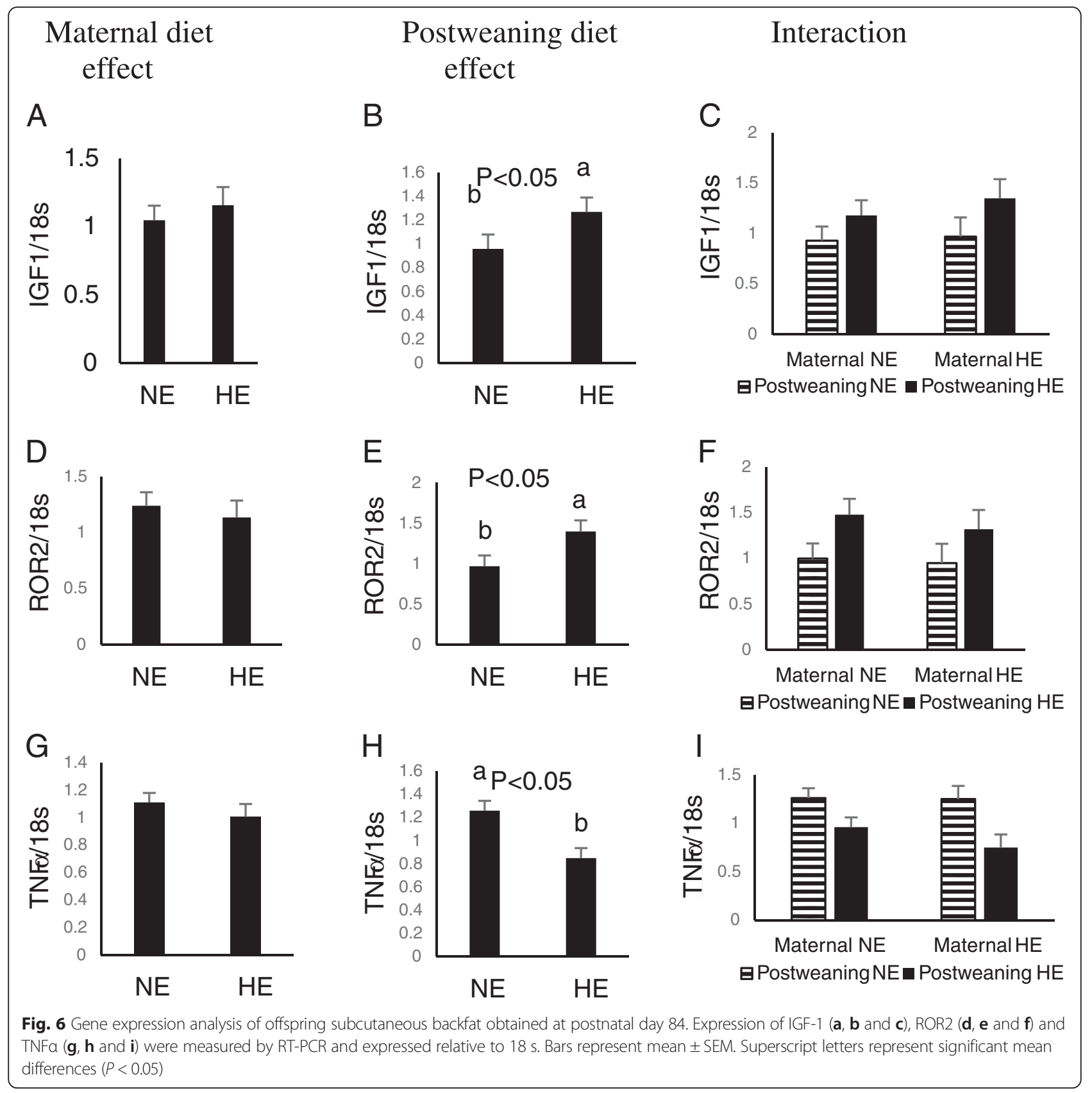

\section{Clinical implication}

Developmental plasticity extends past gestation to include neonatal life $[30,31]$. The data obtained at 3 weeks fall within this perinatal programming window. Indeed, increased expression of multiple genes at 3 weeks suggest a significant maternal effect. Higher expression of genes involved in differentiation (PPAR $\gamma, \mathrm{CEBP} \alpha$ and FABP4, fatty acid binding protein 4) suggest increased differentiation potential in HE offspring at weaning, because these genes are known to directly increase adipocyte differentiation and are induced in several models of obesity [32]. The lower expression of NCOR1, a transcriptional suppressor of PPAR $\gamma$, and the upregulation of SETD8 (a transcriptional activator of PPAR $\gamma$ ) and wnt inhibitors (SFRP4 and SFRP5), also provide evidence that offspring from the HE gilts have increased adipogenic potential at 3 weeks. The induction of GCCR in offspring from HE gilts is consistent with the established effect of glucocorticoids in increasing adipogenesis [33]. However, higher expression of SIRT1, SETDB1 and FZD2, negative regulators of PPAR $\gamma$ and adipogenesis [34-36] also suggests that HE diet may induce negative feedback mechanisms to limit adipose tissue expansion in the offspring. The lower expression of IL1 $\beta$ in HE 
piglets indicates lower inflammation status and suggests a healthy adipose tissue expansion in the HE offspring. This is not surprising as the gene expression profile suggests a higher PPAR $\gamma$ activity at 3 weeks, and increased PPAR $\gamma$ activity is associated with increased adipose tissue expansion but reduced inflammation [37]. This phenomenon is known as healthy adipose tissue expansion due to the lack of inflammation [38]. This is in contrast to pathological adipose tissue expansion that may be accompanied by increased inflammation [39]. The increased expression of adipogenic genes in the adipose tissue of HE gilts may be tied to the increased lipid (and presumably energy) content of the milk from HE gilts. As previously established, offspring exposed to a calorierich suckling period exhibit increased adiposity, hyperleptinemia and hypertension during adulthood [40]. In addition, pups reared in small litters, which presumably have access to greater food supply, exhibit adipocyte hyperplasia and obesity by the end of a 21-day suckling period [41]. Artificially reared pups on a high carbohydrate diet during the suckling period also experience increased adiposity [9]. Thus, increased maternal calorie consumption during gestation may predispose offspring to early increase in adipose tissue expansion which may lead to future obesity.

However, at 12 weeks of age, most of the programming effects seen in the adipose tissue at 3 weeks had completely disappeared, and the effect of the postweaning HE diet was predominant. The higher expression of NCOR1 and SFRP5 in pigs on postweaning HE diet is consistent with increased adipogenic potential from the postweaning HE diet. However, negative regulators of adipogenesis, Wnt5a and ROR2 (receptor tyrosine kinase-like orphan receptor 2), were also induced, potentially to limit adipose accretion from the HE diet. Nevertheless, the tendency $(P<0.09)$ for a lower ratio of Wnt5a/SFRP5 and higher IGF-1 support an increased adipogenic potential on the post weaning HE diet. A healthy adipose expansion may be occurring as a result of the HE diet as expression of TNFa (tumor necrosis factor- $\alpha$ ) was lower on the HE diet than the NE. This is reflected in the higher backfat in the offspring on the postweaning HE diet. Thus, although effects of high maternal calorie consumption is reflected in increased capacity for adipose tissue expansion in early life in the offspring, these effects may not be permanent and postweaning diets may alter the effects of maternal gestational diet on the risk for obesity development.

\section{Limitations}

Because the pigs were killed at 12 weeks of age, we were not able to determine the final effect of both gestational and postweaning HE diets on adiposity in adult pigs. However, our data support a significant programming of adiposity by maternal and immediate postnatal dietary energy intake. The effects of these initial periods on the final adiposity in the mature offspring will need longer term studies than was done in the current study.

\section{Conclusions}

Effects of the higher energy content in the maternal and postweaning diets are observable in the adipose tissue in the offspring, potentially setting the stage for greater adiposity in adulthood. Thus, the pig represents an excellent animal model for investigating the effects of both maternal and offspring dietary energy consumption on offspring capacity for adipose tissue deposition. Therefore, unlike human infants, the pig model can be used for determining adipose tissue programming across all ages in the offspring.

\section{Abbreviations}

BMI, Body Mass Index; CEBPa, CCAAT Enhancer Binding Protein a; FZD2, Frizzled Class Receptor 2; GCCR, Glucocorticoid Receptor; HE, High Energy; IL1 $\beta$, Interleukin 13; IOM, Health Institute of Medicine; NCOR1, Nuclear Receptor Corepressor 1; NE, Normal Energy; NEFA, Non-Esterified Fatty Acid; Pgcla, Peroxisome ProliferatorActivated Receptor Gamma Coactivator-1a; PPARY, Peroxisome Proliferator Activated Receptor Gamma; SETD8, SET Domain containing (lysine methyltransferase 8; SFRP2, Secreted Frizzled-Related Protein 2; SIRT1, Sirt1, NAD-dependent Deacetylase Sirtuin-1; SRC1, Steroid Receptor Coactivator-1

\section{Acknowledgements}

Authors acknowldge assistance from Meliza Ward, Hui Yan, Jim Emilson, Darryl Ragland and Hang Lu for animal health and husbandry support.

\section{Funding}

The authors acknowledge funding support from the Showalter Foundation.

Availability of data and materials

All supporting data is contained within the manuscript.

\section{Authors' contributions}

KMA and SSD designed the study, EAL KMA and SSD assisted in collecting all swine data, analyzed and interpreted data, and wrote the manuscript. All authors approved the final version.

\section{Competing interests}

The authors declare that they have no competing interests.

\section{Consent to publication}

Not applicable.

\section{Ethics approval and consent to participate}

This study was carried out in strict accordance with the recommendations in the Guide for the Care and Use of Laboratory Animals of the National Institutes of Health. The Purdue Animal Care and Use Committee (PACUC) approved all procedures on care and use of pigs described in this study.

\section{Author details}

${ }^{1}$ Department of Animal Sciences, Lilly Hall of Life Science, Purdue University, 915 W. State Street, West Lafayette, IN 47907-2054, USA. ${ }^{2}$ Interdepartmental Nutrition Program, Purdue University, West Lafayette, IN, USA. ${ }^{3}$ Current Address: The University of Texas Medical Branch at Galveston, Galveston, Texas 77555-0144, USA.

Received: 8 October 2015 Accepted: 27 May 2016

Published online: 01 June 2016

References

1. Butte NF, Ellis KJ, Wong WW, Hopkinson JM, Smith EO. Composition of gestational weight gain impacts maternal fat retention and infant birth weight. Am J Obstet Gynecol. 2003;189(5):1423-32. 
2. Viswanathan M, Siega-Riz AM, Moos MK, Deierlein A, Mumford S, Knaack J, Thieda P, Lux $\sqcup$, Lohr KN. Outcomes of maternal weight gain. Evid Rep Technol Assess (Full Rep). 2008;168:1-223.

3. Crane MG, White J, Murphy P, Burrage LDH. The effect of gestational weight gain by body mass index on maternal and neonatal outcomes. J Obstet Gynaecol Can. 2009;31(1):28-35.

4. Oken E, Taveras EM, Kleinman KP, Rich-Edwards JW, Gillman MW. Gestational weight gain and child adiposity at age 3 years. Am J Obstet Gynecol. 2007;196(4):322. e321-328.

5. Wrotniak BH, Shults J, Butts S, Stettler N. Gestational weight gain and risk of overweight in the offspring at age $7 \mathrm{y}$ in a multicenter, multiethnic cohort study. Am J Clin Nutr. 2008;87(6):1818-24.

6. Crozier SR, Inskip HM, Godfrey KM, Cooper C, Harvey NC, Cole ZA, Robinson SM. Weight gain in pregnancy and childhood body composition: findings from the Southampton Women's Survey. Am J Clin Nutr. 2010;91(6):1745-51.

7. Fraser A, Tilling K, Macdonald-Wallis C, Sattar N, Brion MJ, Benfield L, Ness A, Deanfield J, Hingorani A, Nelson SM, Smith GD, Lawlor DA. Association of maternal weight gain in pregnancy with offspring obesity and metabolic and vascular traits in childhood. Circulation. 2010;121(23):2557-64.

8. Van Lieshout RJ, Taylor VH, Boyle MH. Pre-pregnancy and pregnancy obesity and neurodevelopmental outcomes in offspring: a systematic review. Obes Rev. 2011;12(5):e548-559.

9. Srinivasan M, Mitrani P, Sadhanandan G, Dodds C, Shbeir-EIDika S, Thamotharan S, Ghanim H, Dandona P, Devaskar SU, Patel MS. A highcarbohydrate diet in the immediate postnatal life of rats induces adaptations predisposing to adult-onset obesity. J Endocrinol. 2008;197(3):565-74.

10. Zambrano E, Martinez-Samayoa PM, Rodriguez-Gonzalez GL, Nathanielsz PW. Dietary intervention prior to pregnancy reverses metabolic programming in male offspring of obese rats. J Physiol. 2010;588(Pt 10):1791-9.

11. Armitage JA, Khan IY, Taylor PD, Nathanielsz PW, Poston L. Developmental programming of the metabolic syndrome by maternal nutritional imbalance: how strong is the evidence from experimental models in mammals? J Physiol. 2004;561(Pt 2):355-77.

12. Gallou-Kabani C, Vigé A, Gross MS, Boileau C, Rabes JP, Fruchart-Najib J, Jais JP, Junien C. Resistance to high-fat diet in the female progeny of obese mice fed a control diet during the periconceptual, gestation, and lactation periods. Am J Physiol Endocrinol Metab. 2007;292(4):E1095-1100.

13. Khan IY, Dekou V, Douglas G, Jensen R, Hanson MA, Poston L, Taylor PD. A high-fat diet during rat pregnancy or suckling induces cardiovascular dysfunction in adult offspring. Am J Physiol Regul Integr Comp Physiol. 2005; 288(1):R127-133.

14. Kirk SL, Samuelsson AM, Argenton M, Dhonye H, Kalamatianos T, Poston L, Taylor $\mathrm{PD}$, Coen CW. Maternal obesity induced by diet in rats permanently influences central processes regulating food intake in offspring. PLoS One. 2009;4(6):e5870

15. Arentson-Lantz EJ, Buhman KK, Ajuwon K, Donkin SS. Excess pregnancy weight gain leads to early indications of metabolic syndrome in a swine model of fetal programming. Nutr Res. 2014;34(3):241-9.

16. Patience JF, Shand P, Pietrasik Z, Merrill J, Vessie G, Ross KA, Beaulieu AD The effect of ractopamine supplementation at $5 \mathrm{ppm}$ of swine finishing diets on growth performance, carcass composition and ultimate pork quality. Can J Anim Sci. 2009:89:53-66.

17. Johnson JL, Farr SL, Dietz PM, Sharma AJ, Barfield WD, Robbins CL. Trends in gestational weight gain: the pregnancy risk assessment monitoring system, 2000-2009. Am J Obstet Gynecol. 2015;212(6):806. e1-8.

18. Ctripw G, lomnr C. In: KM Rasmussen AY, editor. Weight gain during pregnancy: reexamining the guidelines. US: National Academies Press; 2009.

19. Ludwig DS, Currie J. The association between pregnancy weight gain and birthweight: a within-family comparison. Lancet. 2010;376(9745):984-90.

20. Stirrat GM, Jacobs HS, Klopper A: Clinical physiology in obstetrics; Hytten F, Chamberlain G, editors: Blackwell Scientific Publications, Oxford, 1980.

21. Sohlström A, Forsum E. Changes in adipose tissue volume and distribution during reproduction in Swedish women as assessed by magnetic resonance imaging. The Am J Clin Nutr. 1995;61(2):287-95.

22. Taggart NR, Holliday RM, Billewicz WZ, Hytten FE, Thomson AM. Changes in skinfolds during pregnancy. Br J Nutr. 1967;21(2):439-51.

23. Wakabayashi K, Okamura M, Tsutsumi S, Nishikawa NS, Tanaka T, Sakakibara I, Kitakami J, Ihara S, Hashimoto Y, Hamakubo T, Kodama T, Aburatani H, Sakai J. The peroxisome proliferator-activated receptor gamma/retinoid $X$ receptor alpha heterodimer targets the histone modification enzyme PR-Set7/Setd8 gene and regulates adipogenesis through a positive feedback loop. Mol Cell Biol. 2009;29(13):3544-55.

24. Fu Q, McKnight RA, Yu X, Wang L, Callaway CW, Lane RH. Uteroplacental insufficiency induces site-specific changes in histone $\mathrm{H} 3$ covalent modifications and affects DNA-histone $\mathrm{H3}$ positioning in day 0 IUGR rat liver. Physiol Genomics. 2004;20(1):108-16.

25. Aagaard-Tillery KM, Grove K, Bishop J, Ke X, Fu Q, McKnight R, Lane RH. Developmental origins of disease and determinants of chromatin structure: maternal diet modifies the primate fetal epigenome. J Mol Endocrinol. 2008; 41(2):91-102.

26. Lizcano F, Vargas D. Diverse coactivator recruitment through differential PPARgamma nuclear receptor agonism. Genet Mol Biol. 2013;36(1):134-9.

27. Surana R, Sikka S, Cai W, Shin EM, Warrier SR, Tan HJ, Arfuso F, Fox SA, Dharmarajan AM, Kumar AP. Secreted frizzled related proteins: Implications in cancers. Biochim Biophys Acta. 2014;1845(1):53-65.

28. Park JR, Jung JW, Lee YS, Kang KS. The roles of Wnt antagonists Dkk1 and SFRP4 during adipogenesis of human adipose tissue-derived mesenchymal stem cells. Cell Prolif. 2008;41(6):859-74.

29. Ehrlund A, Mejhert N, Lorente-Cebrián S, Aström G, Dahlman I, Laurencikiene J, Rydén M. Characterization of the Wnt inhibitors secreted frizzled-related proteins (SFRPs) in human adipose tissue. J Clin Endocrinol Metab. 2013:98(3):E503-508.

30. Hanson MA, Gluckman PD. Developmental origins of health and disease: moving from biological concepts to interventions and policy. Int J Gynaecol Obstet. 2011;115 Suppl 1:S3-5.

31. Taylor PD, Poston L. Developmental programming of obesity in mammals. Exp Physiol. 2007;92(2):287-98.

32. Zuo Y, Qiang L, Farmer SR. Activation of CCAAT/enhancer-binding protein (C/EBP) alpha expression by C/EBP beta during adipogenesis requires a peroxisome proliferator-activated receptor-gamma-associated repression of HDAC1 at the C/ebp alpha gene promoter. J Biol Chem. 2006;281(12):7960-7.

33. Ringold GM, Chapman AB, Knight DM. Glucocorticoid control of developmentally regulated adipose genes. J Steroid Biochem. 1986;24(1):69-75.

34. Picard F, Kurtev M, Chung N, Topark-Ngarm A, Senawong T, Machado De Oliveira R, Leid M, McBurney MW, Guarente L. Sirt1 promotes fat mobilization in white adipocytes by repressing PPAR-gamma. Nature. 2004; 429(6993):771-6.

35. Takada I, Kouzmenko AP, Kato S. Molecular switching of osteoblastogenesis versus adipogenesis: implications for targeted therapies. Expert Opin Ther Targets. 2009;13(5):593-603.

36. Ahn J, Lee H, Kim S, Ha T. Curcumin-induced suppression of adipogenic differentiation is accompanied by activation of Wnt/ 3 -catenin signaling. Am J Physiol Cell Physiol. 2010;298(6):C1510-1516.

37. Tsuchida A, Yamauchi T, Takekawa S, Hada Y, Ito Y, Maki T, Kadowaki T. Peroxisome Proliferator-Activated Receptor (PPAR) Activation Increases Adiponectin Receptors and Reduces Obesity-Related Inflammation in Adipose Tissue: Comparison of Activation of PPAR, PPAR, and Their Combination. Diabetes. 2005:54(12):3358-70.

38. Petrovic N, Walden TB, Shabalina IG, Timmons JA, Cannon B, Nedergaard J. Chronic peroxisome proliferator-activated receptor gamma (PPARgamma) activation of epididymally derived white adipocyte cultures reveals a population of thermogenically competent, UCP1-containing adipocytes molecularly distinct from classic brown adipocytes. J Biol Chem. 2010; 285(10):7153-64.

39. Lumeng $C N$, Bodzin $J$, Saltiel AR. Obesity induces a phenotypic switch in adipose tissue macrophage polarization. J Clin Invest. 2007;117(1):175-84.

40. Plagemann A. Perinatal programming and functional teratogenesis: impact on body weight regulation and obesity. Physiol Behav. 2005;86(5):661-8.

41. Schmidt I, Fritz A, Schölch C, Schneider D, Simon E, Plagemann A. The effect of leptin treatment on the development of obesity in overfed suckling Wistar rats. International journal of obesity and related metabolic disorders : Journal of the International Association for the Study of Obesity. 2001;25(8):1168-74 